\title{
Effects of Grain Size and Texture on Thermal Conductivity of AZ31 during Static Recrystallization
}

\author{
Gun-Young $\mathrm{Oh}^{1,{ }^{* 1}}$, Young-Kyun $\mathrm{Kim}^{1}$, Shae K. Kim ${ }^{1}$, Hyun Kyu Lim ${ }^{1,{ }^{2}}$ and Young-Jig Kim ${ }^{2}$ \\ ${ }^{1}$ Advanced Process and Materials R\&D Group, Korea Institute of Industrial Technology, Incheon 21999, Republic of Korea \\ ${ }^{2}$ School of Advanced Materials Science and Engineering, Sungkyunkwan University, Suwon 16419, Republic of Korea
}

\begin{abstract}
In this paper, we report the effect of grain size and texture on the thermal conductivity of AZ31 alloys during static recrystallization. The ND surface of the extruded sheet had higher thermal conductivity than the cast material with random texture. As the recrystallization progresses after extrusion, the thermal conductivity tends to increase. It is considered that this is a composite cause of the growth of the grain, decrease of the grain size and development of strong basal texture. [doi:10.2320/matertrans.M2017126]
\end{abstract}

(Received April 13, 2017; Accepted June 6, 2017; Published June 30, 2017)

Keywords: grain size, texture, thermal conductivity, microstructure, static recrystallization

\section{Introduction}

Magnesium alloy systems are attracting attention as a structural material because of their low density, high specific strength and stiffness. ${ }^{1,2)}$ Among the recent trends in thinning and miniaturization of electronic devices, consumers are demanding smaller and lighter electronic devices. ${ }^{3,4)}$ There are many researches on the casting process and plastic deformation such as extrusion, rolling and etc. for internal and external materials, ${ }^{5-7)}$ but there is no attempt made to solve the heat generation problem of electronic devices which can result from long term use. In order to solve this heat generation problem, it is a great challenge to increase the thermal conductivity while maintaining a good mechanical properties of the Mg alloy. ${ }^{8,9)}$ To ensure the mechanical properties of the $\mathrm{Mg}$ alloy, the grain size, the relationship between the matrix, the second phase and the texture after plastic deformation must be controlled. ${ }^{10)}$ In addition, the static recrystallization which is indispensable after plastic deformation must be considered because the recrystallization after plastic deformation is a process that must be followed to stabilize the internal energy of plastic deformed material. ${ }^{11)}$ Previous researches on thermal conductivity of $\mathrm{Mg}$ alloys have been mainly concerned with the thermal conductivity versus mechanical properties due to precipitation of the second phase in the matrix, ${ }^{12)}$ but the studies on the post-recrystallization phenomena are scarce. Therefore, the aim of the present study is to investigate the effect of grain size and texture on thermal conductivity during static recrystallization after hot extrusion of AZ31 alloy, which is the most well-known of magnesium alloys.

\section{Experimental Procedure}

The alloy billet with a nominal composition of AZ31 alloy were prepared in an electrical resistance furnace under a mixture of $\mathrm{SF}_{6}$ and $\mathrm{CO}_{2}$ protective gas atmosphere using high purity commercial $\mathrm{Mg}, \mathrm{Al}, \mathrm{Zn}$ and $\mathrm{Mg}-5 \mathrm{Mn}$. Molten metal was poured into a preheated $(\sim 373 \mathrm{~K})$ cylindrical steel

\footnotetext{
${ }^{* 1}$ Graduate Student, Sungkyunkwan University

${ }^{* 2}$ Corresponding author, E-mail: hklim@kitech.re.kr
}

mold $90 \mathrm{~mm}$ in diameter and $160 \mathrm{~mm}$ in height. This billet was homogenized at $623 \mathrm{~K}$ for 24 hours and followed by water-quenching. The sample was then extruded at $623 \mathrm{~K}$ with an extrusion ratio of 20:1 and 10:1. The XRD patterns were acquired from the polished samples. Electron back-scattering diffraction (EBSD) analysis was used for characterization of the microstructures and texture of as-extruded and static recrystallized samples. For the sample preparation for EBSD, the surface of the samples was mechanically ground with $\mathrm{SiC}$ paper and then ion-milled. The EBSD data were processed using TSL-OIM analysis software and the data points with a confidence index lower than 0.1 were removed from the EBSD data. The thermal conductivities of the alloys were measured at a temperature ranging from $298 \mathrm{~K}$ to $473 \mathrm{~K}$ with a NETZSCH model LFA447 Flash Analyzer. The size of the specimen was $\Phi 12.7 \times$ $2 \mathrm{~mm}$. The thermal conductivity, $\lambda\left(\mathrm{Wm}^{-1} \mathrm{~K}^{-1}\right)$, was calculated from the diffusivity and specific heat using the following equation:

$$
\lambda=\alpha \cdot \rho \cdot \mathrm{C}_{\mathrm{p}}
$$

where $\alpha$ is the thermal diffusivity; $\rho$ is the density; and $\mathrm{C}_{\mathrm{p}}$ is the specific heat capacity.

\section{Results and Discussions}

Figure 1(a) shows the XRD results of as-cast and extruded sheet with an extrusion ration of 10:1 as three direction (normal direction (ND), extrusion direction (ED) and transverse direction (TD)). Since the minimum sample size for thermal conductivity is $\Phi 12.7 \mathrm{~mm} \times 2 \mathrm{~mm}$, a test sample with a relatively small extrusion ratio was selected to observe the variation of thermal conductivity as a sample direction after extrusion. The as-cast sample had a random texture, and the extruded sheet had a strong anisotropy in basal texture to the ND. This result has been reported by many researchers and is a typical result of $\mathrm{Mg}$ alloys. ${ }^{13,14)}$ The exact anisotropy of texture must be confirmed the using a pole figure by XRD or EBSD. However, according to report by Lim et al., the volume fraction of intensity by XRD practically coincided with the result of the pole figure. ${ }^{15)}$ Our results show that the exact intensity ratio between basal and non-basal plane does 
not affect the thermal conductivity, but rather the tendency of the basal plane to exist in the preferred orientation. Figure 1(b) shows the temperature and texture dependency in thermal conductivity of the tested samples. Overall, the higher the measuring temperature, the more the thermal conductivity tends to increase. Because the thermal conductivity depends on the thermal diffusivity and the specific heat capacity as shown in the eq. (1) in the experimental procedure, so it is obtained because of the increase of these two parameters. ${ }^{16)}$ The ND sample of the extruded sheet had the highest thermal conductivity. The extruded sheet compared to ascast samples having random texture shows a significant difference depending on the measuring direction. In particular, the ND sample with a strong basal texture has a higher thermal conductivity than the non-basal direction. This has been reported that a plastic deformed $\mathrm{Mg}$ alloys generally has a strong basal texture and a difference in thermal conductivity as direction of sheet. Mainly, ND specimen with a strong basal texture has the highest thermal conductivity. This remarkable difference in thermal conductivity is due to the crystal orientation and the strong basal fiber texture is developed to the ND.,6) Figure 2 (a)-(e) shows the inverse pole figure (IPF) maps and (0002) pole figures of the samples with a static recrystallization time of the extruded sheet. In addition, Fig. 2 (f) shows a variation in thermal conductivity measured at room temperature of the specimen in Fig. 2 (a)(e). The sample in Fig. 2 is extruded with a high extrusion ratio of 20:1. Since our study is about the effect of grain size and texture on the thermal conductivity, so we selected the sample with a relatively high extrusion ratio. After extrusion, the microstructure was coexisted with locally non-plastic deformed coarse grains and dynamic recrystallized several micrometer sized grains. As the static recrystallization proceeds, the grain size and thermal conductivity tended to in-
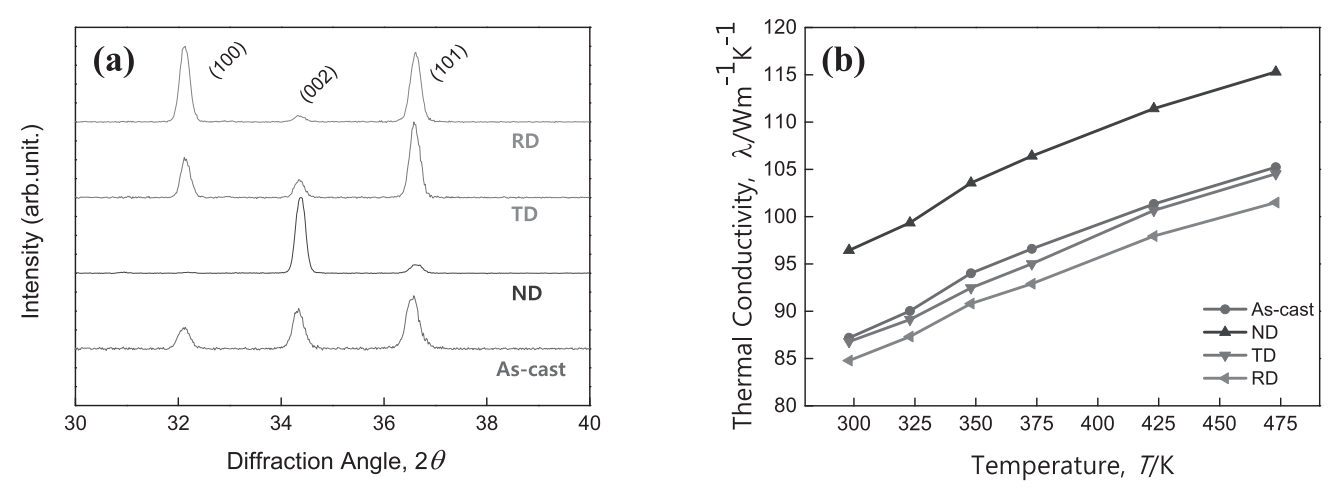

Fig. 1 (a) XRD results of as-cast and extruded sheet as plane directions, (b) thermal conductivities of (a) samples at various temperatures.
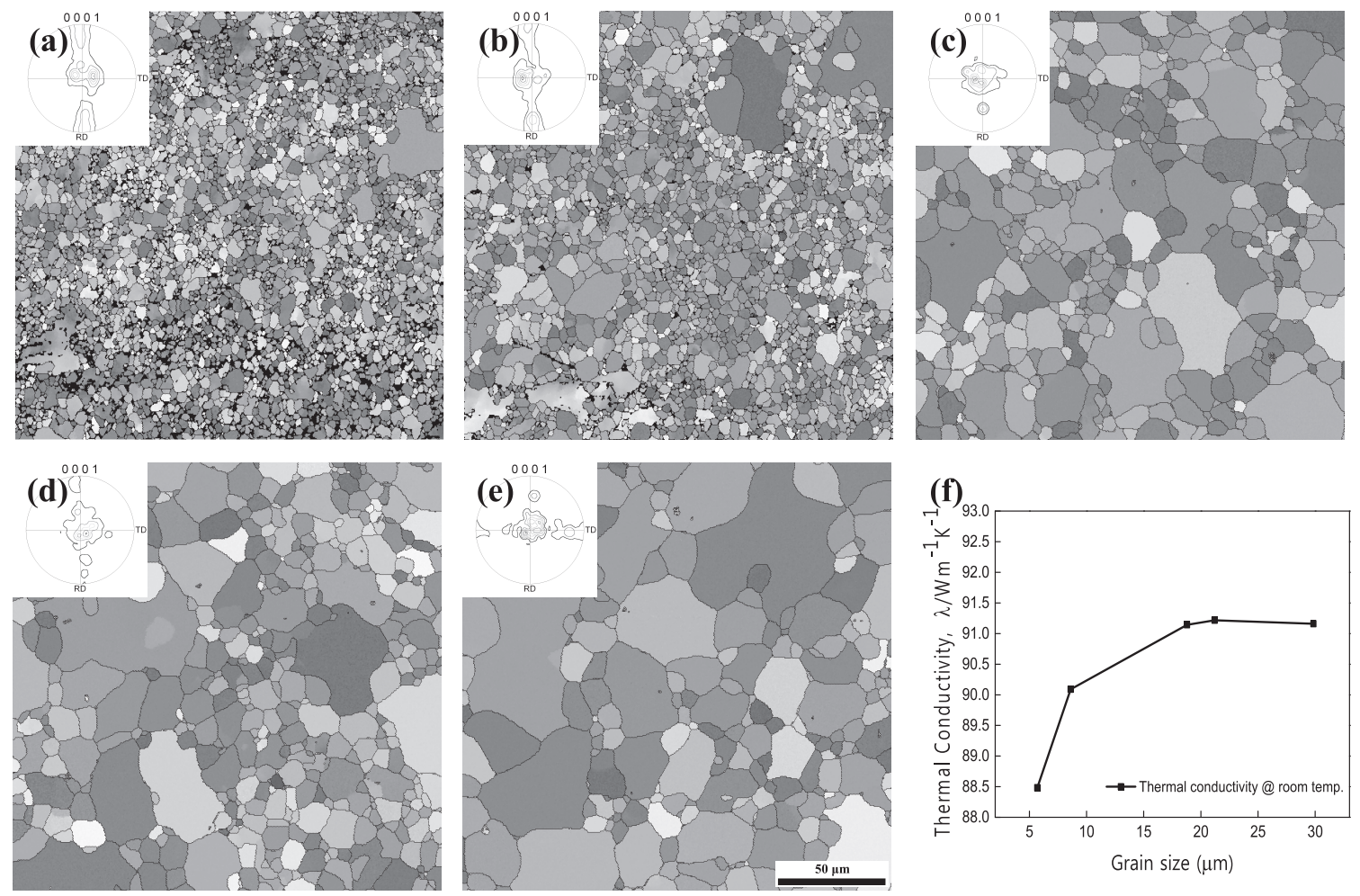

Fig. 2 Texture evolution and variations of grain size and thermal conductivities as recrystallization time, (a) as-extruded, (b) 4 hr, (c) 24 hr, (d) 48 hr, (e) $72 \mathrm{hr}$ and (f) thermal conductivities. 
Table 1 The variation of grain size, the intensity of basal texture and the volume fraction of the misorientation angle during the static recrystallization.

\begin{tabular}{cccccc}
\hline Sample & Condition & Grain size & Intensity & HAGB & LAGB \\
\hline $\mathrm{a}$ & As-extruded & $5.7 \mu \mathrm{m}$ & 11.1 & 62.3 & 37.7 \\
\hline $\mathrm{b}$ & $350^{\circ} \mathrm{C}, 4 \mathrm{hr}$ & $8.6 \mu \mathrm{m}$ & 15.5 & 69.9 & 30.1 \\
\hline $\mathrm{c}$ & $350^{\circ} \mathrm{C}, 24 \mathrm{hr}$ & $18.8 \mu \mathrm{m}$ & 15.5 & 87.6 & 12.4 \\
\hline $\mathrm{d}$ & $350^{\circ} \mathrm{C}, 48 \mathrm{hr}$ & $21.2 \mu \mathrm{m}$ & 15.9 & 89.4 & 10.6 \\
\hline $\mathrm{e}$ & $350^{\circ} \mathrm{C}, 72 \mathrm{hr}$ & $29.8 \mu \mathrm{m}$ & 16.6 & 91.3 & 8.7 \\
\hline
\end{tabular}

crease, and the thermal conductivity converged to $91.2 \mathrm{Wm}^{-1} \mathrm{~K}^{-1}$ at an average grain size of about $19 \mu \mathrm{m}$ or more. The absolute thermal conductivity is small compared to the sample in Fig. 1. Because the grain boundaries are one of the factors preventing the free movement of electrons, samples with high extrusion ratios are considered to have low thermal conductivity. Table 1 shows the variation of grain size, the intensity of basal texture and the volume fraction of the misorientation angle during the static recrystallization from the EBSD results. As the grain size increased, the basal texture was strongly developed. According to Smith, grain growth is required the interaction between the topological requirements of space-filling and the geometrical needs of surface tension equilibrium. Thus, the grains with (0002) preferential orientation grow while absorbing a neighboring grains with newly recrystallized random orientation during static recrystallization. ${ }^{17,18)}$ Also, grain growth depends on the temperature and is strongly influenced by the kinetics and the migration of high angle grain boundary (HAGB) that are at least 5 degrees apart from neighboring grain. $\mathrm{Mg}$ alloys with strongly basal texture essentially involved a low angle grain boundary (LAGB) with an angle lower than HAGB, grain growth is inevitably going to reduce driving force for grain growth. ${ }^{11)}$ The completion time of the static recrystallization was assumed to be 24 hours, because the fraction of the HAGB after 24 hours was more than $90 \%$.

From our results, it can be seen that the factors affecting the thermal conductivity during the static recrystallization of AZ31 are complexity of the grain size and the intensity of basal texture. The thermal conductivity in the initial stage of the static recrystallization sharply increased because the grain growth and the intensity of basal texture was greatly increased. In the latter period of static recrystallization, the thermal conductivity is not increased any more since the development of basal texture and the grain growth are smaller than the initial stage of static recrystallization. In other words, the thermal conductivity of the metal is closely related to the mean free path, and these tendency can be suggested that the mean free path is no longer affected on the thermal conductivity above a critical grain size. Although our re- sults show a clear trend for variation in thermal conductivity for two factors, further analysis is needed for a quantitative analysis of the dominant factors.

\section{Conclusion}

In this study, we investigated the effect of grain size and texture on the thermal conductivity of AZ31 alloy during static recrystallization. The thermal conductivity of the ND plane with strong basal texture was higher than that of the cast samples with relatively random texture. In the case of extruded sheet, the values of thermal conductivity have difference according to the direction of plane such as ND, ED and TD, and the ND plane was the highest. As the recrystallization progresses, the thermal conductivity tends to increase. It is considered that this is due to the grain growth and development of strong basal texture at the ND plane.

\section{Acknowledgments}

This work was supported by the National Research Foundation of Korea (NRF) grant funded by the Korea government (Ministry of Science, ICT \& Future Planning) (NRF2016K1A3A1A31953855).

\section{REFERENCES}

1) B.L. Mordike and T. Ebert: Mater. Sci. Eng. A 302 (2001) 37-45.

2) A. Rudajevova and P. Lukac: AUC Mat. Phys. 41 (2000) 3-36.

3) S.H. Lee, H.J. Ham, S.Y. Kwon, S.W. Kim and C.M. Suh: Int. J. Thermophys. 34 (2013) 2343-2350.

4) A. Rudajevova and P. Lukac: Mater. Sci. Eng. A 397 (2005) 16-21.

5) T. Ying, M.Y. Zheng, Z.T. Li and X.G. Qiao: J. Alloy. Compd. 608 (2014) 19-24.

6) T. Ying, M.Y. Zheng, Z.T. Li, X.G. Qiao and S.W. Xu: J. Alloy. Compd. 621 (2015) 250-255.

7) H. Pan, F. Pan, J. Peng, A. Tang, J. Gou, L. Wu and H. Dong: J. Alloy. Compd. 578 (2013) 493-500.

8) J. Yuan, K. Zhang, T. Li, X. Li, Y. Li, M. Ma, P. Luo, G. Luo and Y. Hao: Mater. Des. 40 (2012) 257-261.

9) L. Zhong, J. Peng, M. Li, Y. Wang, Y. Lu and F. Pan: J. Alloy. Compd. 661 (2016) 402-410.

10) G. Nussbaum, P. Sainfort, G. Regazzoni and H. Gjestland: Scr. Metall. Mater. 23 (1989) 1079-1084.

11) F. J. Humphreys, M. Hatherly: Recrystallization and Related Annealing Phenomena, (Elsevier Ltd. Oxford, 2004) p.446.

12) H. Pan, F. Pan, R. Yang, J. Peng, C. Zhao, J. She, Z. Gao and A. Tang: J. Mater. Sci. 49 (2014) 3107-3124.

13) Y.N. Wang and J.C. Huang: Mater. Trans. 48 (2007) 184-188.

14) K.P. Rao, Y.V.R.K. Prasad, J. Dzwonczyk, N. Hort, K.U. Kainer: Metals 2 (2012) 292-312.

15) H.K. Lim, D.H. Kim, J.Y. Lee, J.S. Kyeong, W.T. Kim and D.H. Kim: Met. Mater. Int. 15 (2009) 337-343.

16) H. Pan, F. Pan, R. Yang, J. Peng, C. Zhao, J. She, Z. Gao and A. Tang: J. Mater. Sci. 49 (2014) 3107-3124.

17) C.S. Smith: Trans. Metall. AIME 175 (1948) 15-51.

18) C.S. Smith: Acta Metall. 1 (1953) 299-300. 